\title{
Endoscopic removal of a large rectal foreign body using a large balloon dilator: report of a case and description of the technique
}

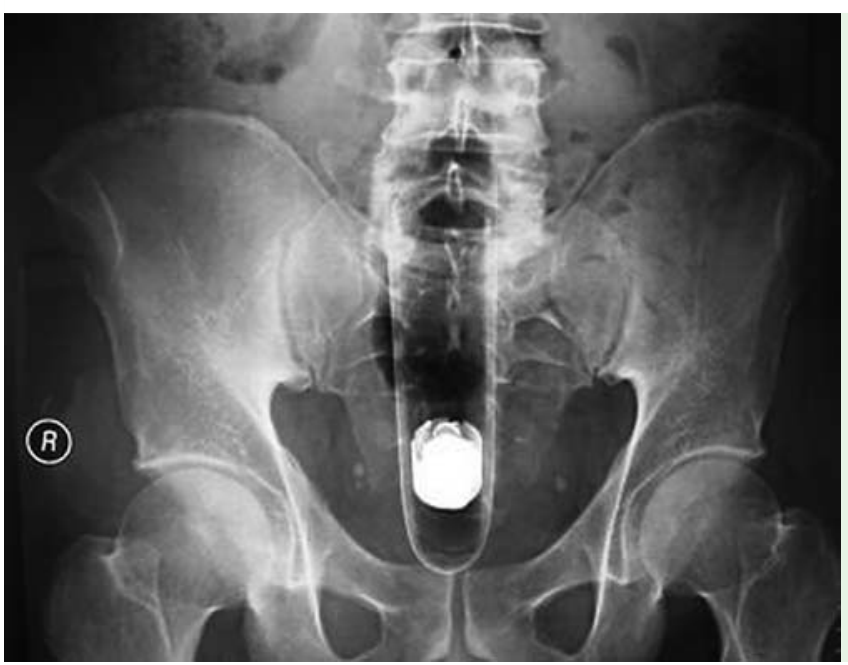

Fig. 1 Radiographic view the vibrator inserted in the reverse position.

Retained rectal foreign bodies are commonly encountered, and various shapes and sizes have been described. Although many foreign bodies can be extracted safely, some patients require hospitalization and surgery [ $1-3]$.

We report the case of a 54-year-old, symptom-free man who was admitted to the emergency department for a retained large rectal vibrator, which had been inserted in a reverse fashion during sexual activity. An abdominal radiograph showed a well-delineated vibrator (length $21 \mathrm{~cm}$; diameter $35 \mathrm{~mm}$ ) in the rectosigmoid junction with no evidence of bowel perforation ( $\bullet$ Fig. 1). After several unsuccessful transanal attempts to remove the foreign body, the patient was referred to the digestive endoscopy unit. Under deep sedation, a 13-mm endoscope (ES-250WE5, Fujinon Inc., Saitama, Japan) was inserted, which showed the blunt distal tip of the vibrator ( $\bullet$ Fig. 2). However, all attempts to ensnare it with a variety of polypectomy snares, and an inflated wireguided 20-mm balloon dilator (CRE; Microvasive, Boston Scientific, Massachusetts, USA) to gently pull out the foreign body, were ineffective. After substituting the endoscope with another with a diameter of $10 \mathrm{~mm}$ (EG-201FP; Fujinon, Inc., Saitama, Japan), in order to reach beyond the proximal tip of the vibrator, a guide wire, under endoscopic view, was inserted over the foreign body. Then the scope was removed and a 40-mm balloon dilator (Rigiflex; Microvasive, Boston Scientific, Massachusetts, USA) was inserted over the wire. The balloon was inflated and gently retracted while guiding the distal tip of the vibrator with a finger to successfully retrieve it. A check sigmoidoscopy after extraction showed a large superficial mucosa injury, however, the patient was discharged 48 hours later without clinical evidence of complications.

To the best of our knowledge, this report is the first to describe the removal of a large, smooth foreign body from the rectum using a 40-mm, large balloon dilator.

\section{Competing interests: None}

\section{Endoscopy_UCTN_Code_TTT_1AQ_2AH}

P. Billi ${ }^{1}$, M. Bassi ${ }^{1}$, F. Ferrara ${ }^{1}$,

A. Biscardi ${ }^{2}$, S. Villani ${ }^{2}$, F. Baldoni ${ }^{2}$, N. D'Imperio ${ }^{1}$

${ }^{1}$ Gastroenterology and Digestive Endoscopy Unit, Bellaria-Maggiore Hospital, AUSL Bologna, Bologna, Italy

2 Emergency Surgery Unit, Maggiore Hospital, AUSL Bologna, Bologna Italy

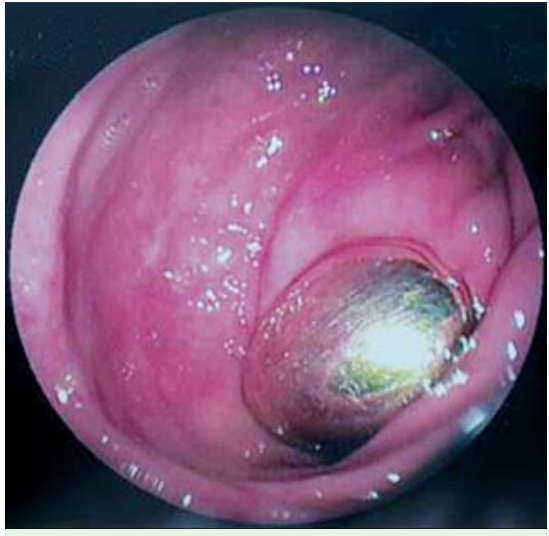

Fig. 2 Endoscopic view of the tip of the vibrator.

\section{References}

1 Cohen JS, Sackler JM. Management of colorectal foreign bodies. J R Coll Surg Edinb 1996; 41: $312-315$

2 Rodríguez-Hermosa JI, Codina-Cazador A, Ruiz $B$ et al. Management of foreign bodies in the rectum. Colorectal Dis 2006; 9: 543 548

3 Goldberg JE, Steele SR. Rectal foreign bodies. Surg Clin North Am 2010; 90: 173-184

\section{Bibliography}

DOI $10.1055 / \mathrm{s}-0030-1255573$

Endoscopy 2010; 42: E238

(c) Georg Thieme Verlag KG Stuttgart · New York . ISSN 0013-726X

\section{Corresponding author \\ P. Billi}

Gastroenterology and Digestive Endoscopy Unit Bellaria-Maggiore Hospital

Largo Nigrisoli 2

AUSL Bologna

Bologna 40133

Italy

Fax: +39-051-6478967

paola.billi@ausl.bologna.it 